\title{
ON THE MARRIAGE-RATES AND BIRTH-RATES OF THE CHIEF COUNTRIES OF EUROPE.
}

\author{
BY HENRY MAY, L.P.C.P., \\ Late Medieal Officer of Health of Aston Manor.
}

THE fall in the marriage-rate and the accompanying fall in the birth-rate of this country have been already considered in these pages*; their probable causes have also been discussed in considerable detail, but these must still be regarded to a large extent as hypothetical. It seems desirable, in order to assist us in forming satisfactory conclusions on this social question, that we should enlarge our field of observation, and endeavour to ascertain how far similar changes have taken place contemporaneously in other countries than our own and obtain some reflected light from them. Even if they are found barren of results in this direction, they will, at least, furnish us with an interesting subject of observation on their own account.

The materials for this comparison are to be found in the tables furnished by the directors of the Statistical Departments of most European countries, and published in the Registrar-Generals' Annual Reports. The statistics are not all suitable for the purposes of comparison, there being none in the case of Russia, and those from Spain being imperfect. It is not worth while taking the very small countries into account. I have referred to England and Wales on former occasions, and propose now to deal with Hungary, Austria, the German Empire, France, Italy, the Netherlands, Switzerland, Belgium, and Sweden. The circumstances of Scotland in regard to its marriage and birth-rates are so similar (except its higher illegitimate birth-rate) to those of England and Wales that it need not be taken into separate account.

The following will be remembered as prominent characteristics of the birth and marriage-rates of England and Wales. The marriagerate attained its highest point in 1873 , and its lowest in 1879 , after a continuous fall during the intervening six years; the birth-rate reached its highest point in 1876 , and its lowest in 1890, after a continuous fall during the fourteen years' interval. I have prepared the following table of the marriage and birth-rates of eleven European countries at these dates, arranging them in the order of their birth-rates, and have added the average annual increase per cent. in the population in the last twenty-five to thirty years.

* See Public Health, x., p. 408; and xi., p. 122. 
Table showing the Marriage-rates of eleven European Countries in 1873 and 1879, also their Birth-rates in 1876 and 1890, with their Annual Increase per cent. in Population.

\begin{tabular}{|c|c|c|c|c|c|c|}
\hline \multirow{2}{*}{ Name of Country. } & \multirow{2}{*}{$\begin{array}{l}\text { Population } \\
\text { in } \\
\text { Millions in } \\
1896 .\end{array}$} & \multicolumn{2}{|c|}{ Marriage-rate in } & \multicolumn{2}{|c|}{ Birth-rate in } & \multirow{2}{*}{$\begin{array}{c}\text { A verage } \\
\text { annual inerease } \\
\text { per cent. } \\
\text { in Population. }\end{array}$} \\
\hline & & 1873. & $18 \% 9$. & 1876. & 1890. & \\
\hline Hungary & $18 \cdot 4$ & $22 \cdot 6$ & 20.8 & $45 \cdot 8$ & $40 \cdot 3$ & $1 \cdot 38$ \\
\hline Austria ..... & $24 * 9$ & $18 \cdot 7$ & $15 \cdot 5$ & $40 \cdot 0$ & $36 \cdot 7$ & 0.87 \\
\hline German Empire & $52 \cdot 7$ & $20 \cdot 0$ & $15 \cdot 0$ & $40 \cdot 9$ & $35 \cdot 7$ & $1 \cdot 12$ \\
\hline Italy ................ & $31 \cdot 9$ & $15 \cdot 8$ & $15 \cdot 2$ & $39 \cdot 2$ & $35 \cdot 9$ & 0.65 \\
\hline Netherlands ....... & $4 \cdot 9$ & $17 \cdot 1$ & $15 \cdot 3$ & $37 \cdot 1$ & $32 \cdot 9$ & $1: 30$ \\
\hline England \& Wales & $30 \cdot 7$ & $17 \cdot 6$ & $14 \cdot 4$ & $36 \cdot 3$ & $30 \cdot 2$ & $1 \cdot 37$ \\
\hline Scotland........ & $4 \cdot 2$ & $15 \cdot 5$ & $12 \cdot 8$ & 356 & $30 * 4$ & 1.00 \\
\hline Switzerland ...... & $3 \cdot 0$ & $15 \cdot 3$ & $13 \cdot 9$ & $33 \cdot 0$ & $26 \cdot 7$ & 0.55 \\
\hline Belgium ......... & $6 \cdot 5$ & $15 \cdot 5$ & $13 \cdot 5$ & $33 \cdot 2$ & $28 \cdot 7$ & $1 \cdot 10$ \\
\hline Sweden............. & $4 \cdot 8$ & $14 \cdot 6$ & $12 \cdot 6$ & $30 \cdot 8$ & $28 \cdot 0$ & $0 \cdot 60$ \\
\hline France .............. & $38 \cdot 1$ & $17 \cdot 6$ & $15 \cdot 1$ & $26 \cdot 2$ & $21 \cdot 8$ & $0 \cdot 12$ \\
\hline
\end{tabular}

Of course, these figures are not intended to show, and do not show, the extent of the fall in countries other than England and Wales, but they show how very elosely a decline in the rates of the others coincided with our own. The amount of uniformity seen in the great changes they indicate is almost startling, and they show that falls in the marriage- and birth-rates took place nearly identically in widely different countries contemporaneously, and commensurate with those in our own. The accompanying chart will serve to show graphically the course of the marriage-rates in six of these countries during the recent thirty years.

High marriage-rates prevailed over a great part of Europe until 1873 , in which year they reached the culminating point, and thenceforth fell rapidly for a definite period (six, seven, or eight years), at the end of which they became irregular until the present time, though with a tendency to rise from their low level. There were exceptionsthus, in Austria this fall was accelerated some years, and occurred in 1869 ; while the rates in Hungary and Italy recovered considerably from their 1874 fall, and the definitive fall in their marriage-rates was delayed until 1883 and 1886 respectively. With these modifications we recognise that in 1874 a sudden change swept over Europe, the characteristic of which was an increased appreciation of celibacy, which continued in active force until about 1880 , when it abated, though it still exerts a depressing influence on the marriage-rates. Belgium alone has recovered its former high level.

Whatever explanation may be given for this, it is one of the

* The rate of increase does not correspond with the birth-rates mainly because of the disturbing effect of different death.rates. 


\section{The Marriage-Rates and Birth-Rates of (Public Health}

important social incidents of our time. There must have been a common origin for this movement of descent in the marriage-rates of so many countries at once. There does not appear to be any one sufficient explanation of it historically. I have ventured to aceount for it-or, rather, made a contribution towards doing so -by the hypothesis that it marks a stage, a temporary one, in the march of civilization, a legitimate development of intelligent egoism, to diminish the burden of parental responsibilities. In plain words, it is not so much a lesser appreciation of matrimony as of paternity and maternity, yet without any growth of illegitimacy. We could

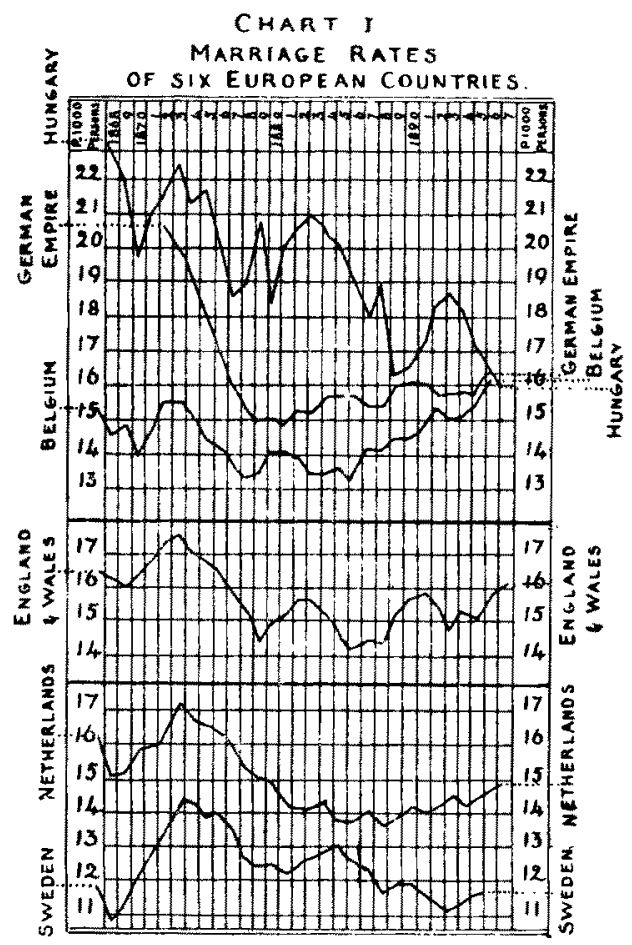

not expect the instincts which conduce to marriage to become permanently cooler and more calculating even under the influence of "a higher civilization," and so we find in these modern prosperous times the marriage-rate in most countries is rising again.

The natural result of this fall in the marriage-rates was the subsequent fall in the birth-rates, postponed for three years, and quite as simultaneous and widely spread as that of the marriagerate, and, further, in some countries out of all proportion in its extent to the natural effects of the latter fall.

At this time the stimulating effect of the peace upon marriage 
had nearly subsided in France and Germany, and there was an unusual and general prevalence of trouble and distress. The general depression in England in 1877 and in Germany in 1878 are matters of history. These would naturally accentuate the fall in the declining marriage-rate, and, coming together with it, would go a long way to explain the suddenness in the birth fall, and also give a start and impulse to a practical Malthusianism, which has remained in spite of altered circumstances.

The accompanying chart will serve to show graphically the course of the birth-rates in seven countries during thirty years, and by

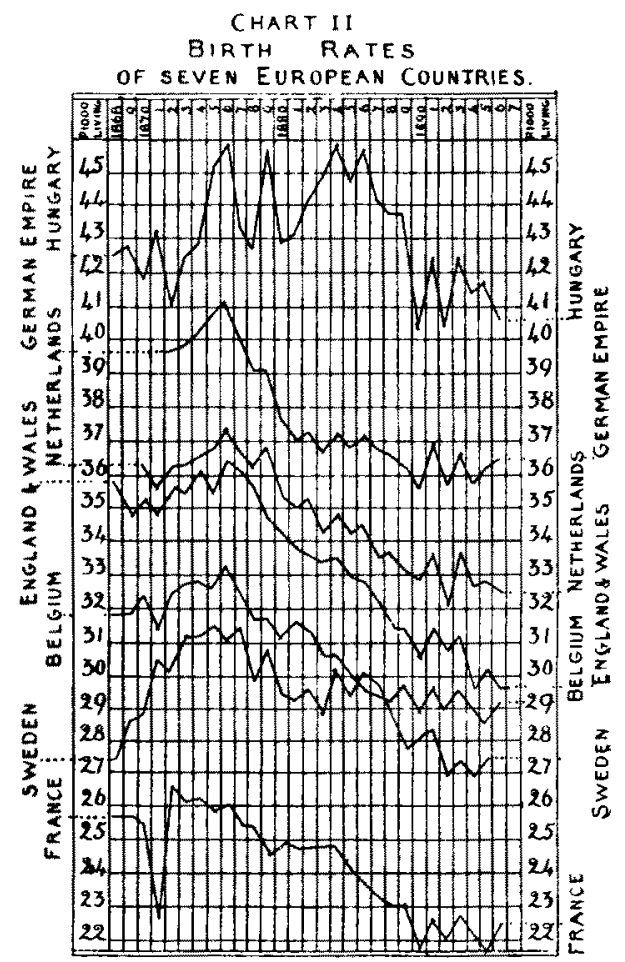

comparing it with the chart of the marriage-rates it will be seen how far there was any mutual parallelism.

The final termination of the downward movement in the birthrates is not very sharply defined, and in some countries it has not yet been reached. The differences in the coursè of the birth-rates subsequent to the first sudden fall throw a considerable light upon their nature and causes. For example, in the great German Empire the accord between the course of the two rates is very definite and typical. The decline in both extends over like periods, and their subsequent course is parallel, so that there is little room 


\section{The Marriage-Rates and Birth-Rates of [Public Health}

for the inference that there was any disturbing influence over the births other than an increase of celibacy, though such an inference must not be altogether excluded.

It is quite different with England and Wales, Belgium, and France, and to a less extent with the Netherlands. Although the marriage-rate of the German Empire fell 24 per cent., the resulting maximum fall in the birth-rate was only $12 \frac{1}{2}$ per cent. The average fall in the marriage-rate in England and Wales was 10 per cent., but, taking the extreme limits, its decline was 19 per cent., and the fall in the birth-rate 17 per cent. instead of 10 per cent., as it should have been according to the German precedent. A similar disproportion is found between the Belgian fall in the marriage-rate of 14 per cent., and in that in the birth-rate of 12 per cent., instead of $6 \frac{1}{2}$ per cent., according to the German precedent. The Belgian marriage-rate has now risen higher than any previously recorded, with a still falling birth-rate. The want of accord between the course of the two rates in recent years in England and Wales is shown on a chart already published.* The same discrepancy exists in the rates of France, and to a smaller extent in the Netherlands.

The conditions attending the course of the birth-rate in France during the last thirty years or so are very complex, but as they are represented on a very large scale in its fairly homogeneous population of thirty-eight millions, they must not be overlooked. France holds decidedly the lowest place in the chart of European birthrates, and yet the corresponding marriage-rate, except when disturbed by the Franco-German War, has not been lower than in this country. It is, however, doubtful if marriage is so much a factor in the birth-rate of France as we are accustomed to regard it elsewhere. It is evident that the infécordité roluntaire is an institution of older date in France, and the effects of the modern impulse in that direction are not so strongly accentuated there as they would otherwise have been. There has, however, been a gradual and well-pronounced fall in its birth and marriage-rates since 1872, and the fact that France has shared simultaneously and correspondingly with this and other countries in the effects of the impulse to which $I$ have referred, coming upon the previously low average birth-rate, affords an additional illustration of its existence and strong evidenee of its force. It has now reduced the birth-rate of that country almost to a level with the death-rate, and the natural increase of France is practically nil.

The relation between the birth and marriage-rates of France for the past forty years are expressed in the accompanying chart.

* Public Health, September, 1898, p. 409. 
These instances in other countries corroborate the explanation which has already been given as to the continued and exaggerated decline in the births of this country out of proportion to the fall in the marriage-rate, and continuing after it has ceased to fall and has established a rise. This explanation is to the effect that a voluntary sterility, which is a feature of modern civilization, must be added to the natural effect of increased celibacy to account for the excep-

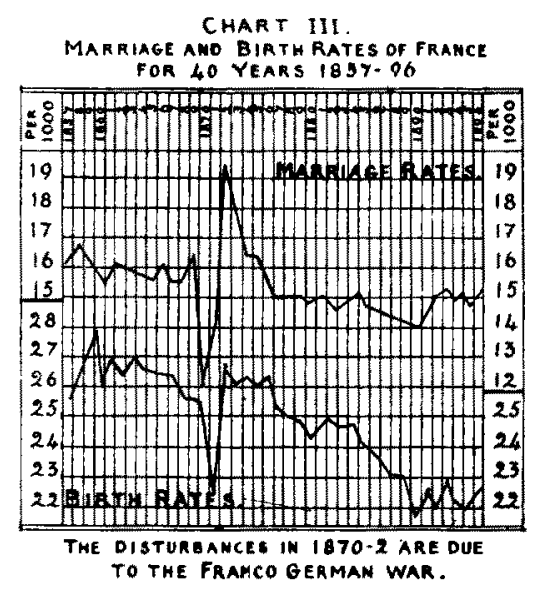

tionally low birth-rates of the present day. It is impossible to say whether the impulse in this direction will be permanent, but there is no sign as yet of its coming to an end.

In conclusion, I cannot but think that the consideration which has been given to the marriage and death-rates of other countries has bad the double advantage of assisting us in arriving at conclusions with reference to our own social problems, and furnishing an interesting field of observation.

Tuberculosis Discussion: A Correction.-In our last number, in an article on Dr. Newsholme's paper on the Prevention of Phthisis, we represented Mr. Shirley Murphy as concurring in Dr. Newsholme's criticism of the action of the Local Government Board concerning the notification of phthisis. Mr. Murphy has asked us to state that he made no reference whatever to the Local Government Board, and that he expressed an opinion adverse to the compulsory notification of phthisis. 